\title{
Does the Culture Service Supply of Green Spaces Match the Demand of Residents in a New District? A Perspective from China
}

\author{
Huabin Xiao', Shuo Sheng ${ }^{2}$, Zhen Ren ${ }^{1}$, Chundi Chen², Yuncai Wang ${ }^{2 *}$ \\ ${ }^{1}$ School of Architecture and Urban Planning, Shandong Jianzhu University, Jinan, China \\ ${ }^{2}$ College of Architecture and Urban Planning, Tongji University, Shanghai, China
}

Received: 18 June 2019

Accepted: 27 October 2019

\begin{abstract}
Building new districts has become one of the most important urbanization methods of the past few decades in China. The planning scheme for new districts pursues the government's and citizens' idea of sustainable development coupled with a livable environment. Green spaces, which connect residents with a natural environment, can provide various kinds of ecosystem services that are essential for human well-being. However, there exists an imbalance of ecosystem services supply and residents' demands, bringing about green inequity in many cities; is the same true in planning-first new districts? This paper proposes a conceptual framework to match the supply and demand of ecosystem services provided by green spaces, by analyzing the ecosystem services sources, the benefiting areas, and residents' distribution and activities. The supply and demand of culture services by public parks in Jinan Western New District was selected to examine the framework. The results show that the supplydemand mismatch exists in every sub-district of the research area. Newly built areas have more supply surplus and supply-demand balanced blocks; over-demand blocks are mainly distributed in old towns, followed by peripheral urban areas. The methods in this study can be used to examine green space distribution in new districts. The findings can then be used to optimize the green space system, which can improve the urban living environment and help achieve social equity.
\end{abstract}

Keywords: green spaces, urban new district, ecosystem services, supply-demand mismatch

\section{Introduction}

\section{Construction of New Districts in China}

In recent decades, China has experienced rapid urbanization; one way to expand an urban area is to construct new districts. The construction of new

*e-mail: wyc1967@tongji.edu.cn

districts in China began in the 1990s with the "Development areas", which focused on industrial development and were the main mode at that time [1]. Since the $21^{\text {st }}$ century, "comprehensive new districts" have become important carriers of economic transition in many regions in China; industry development is no longer the primary purpose of the new districts, and attention has been paid to intensive land-use and ecological environmental protection [2]. The number of new districts in China has increased rapidly in the past 


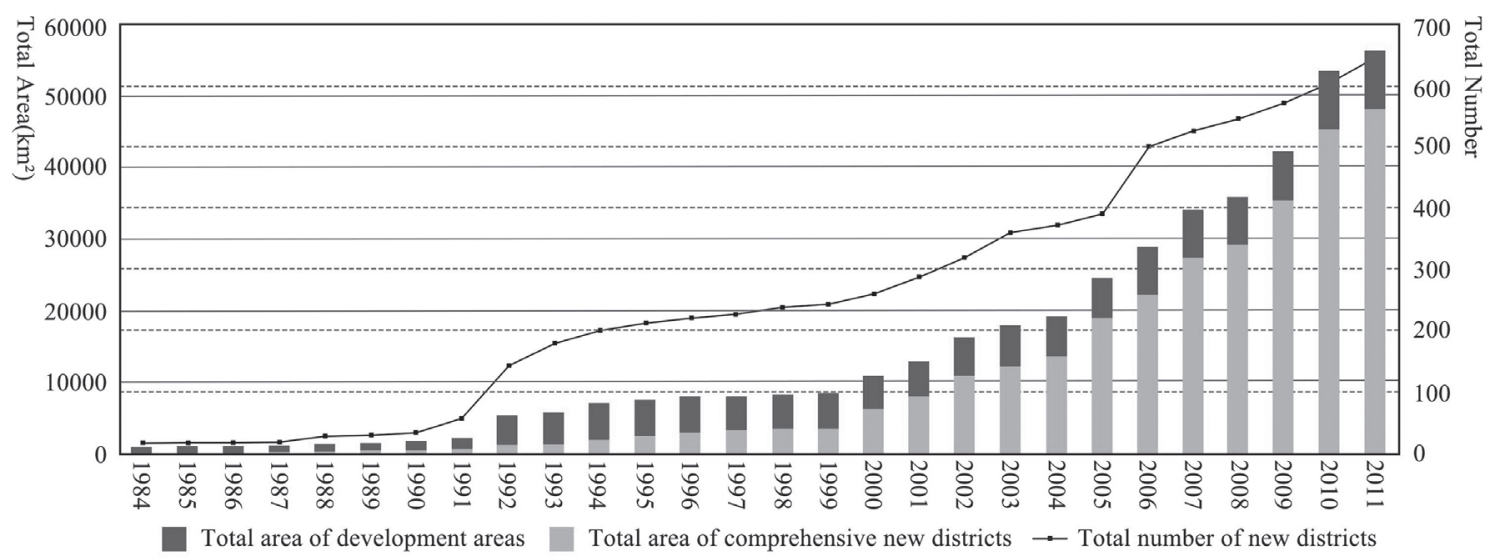

Fig. 1. The total area and number of new districts in China from 1984 to 2011 (redrawn from Zhu's article [2]).

40 years (Fig. 1). According to a report from the State Council of China in 2015, on average each provincial capital has 4.6 new districts and each prefecturelevel city has about 1.5 new districts [3]. Obviously, the construction of new districts has become one of the main approaches to accelerate urbanization and economic transition.

Planning first is a major feature that distinguishes new districts from old towns; development goals such as low carbon, ecology and livability are usually promoted before the construction of new districts. Most new districts designated at the beginning of the 21st century have been completed. Can the new districts achieve the goals in the planning scheme, meet the needs of urban residents, and enable urban residents to enjoy services from urban parks freely? This needs to be demonstrated.

\section{Green Spaces and Ecosystem Services Supply-Demand Mismatch}

Green spaces, especially urban parks, are fundamental elements of cities throughout the world [4]. They provide multiple ecosystem services (ES) that are necessary for urban residents. For example, many parks promote both the physical and psychological health of urban residents by regulating the surrounding microclimate and providing green views and places to do physical activities $[5,6]$. Also, the vegetation ground in green spaces can reduce stormwater runoff, mitigate the urban heat island and support biological diversity $[7,8]$. It is important to have access to green spaces - particularly for urban residents who have limited contact with the natural environment [9].

However, with urbanization, built-up areas have spread into natural spaces nearby, leading to more residents with fewer and more fragmented green spaces, causing an unbalanced supply and demand [10]. Many researchers confirm the widespread evidence of green space inequity throughout the world. Green spaces and the corresponding ecosystem services are not always equitably distributed either in urban areas or the urban periphery. Residents' access to green spaces is generally associated with their age, ethnic-racial characteristics, wealth, education, and other socio-economic features $[11,12]$. The mismatch between green space supply and residents' demands has been recognized as an environmental justice issue and has been taken seriously by both scholars and governments [13].

Many studies have focused on green spaces' ecosystem services supply and demand. Considerably more attention has been devoted to the supply side than the demand one, mainly concentrating on the evaluation of green spaces' supply [14]. For example, one study summarized the total amount of green space in a city and evaluated the total value of the ecosystem services, as a basis to estimate green space supply capacity [15]. Many studies map the service scope of each green space based on the GIS platform, and analyze the walkable accessibility in a certain time or distance $[16,17]$. Estimating the cultural services of green spaces using questionnaires is the most frequently adopted method [18]. Approaches to evaluating users' demands can vary according to researcher's objectives. Several studies surveyed users' preferences, emotions, and perspectives - mostly through questionnaires and interviews, to find out enjoyable green spaces and obtain users' demands, which can be used as guidelines to optimize the supply quality $[19,20]$. Some researchers took population density and economic level as indicators to represent the demand [15]. In many investigations, the residence of green space users was located to map the demand area and corresponding demand degree. By doing so, the supply-demand mismatch areas can be mapped [21, 22]. Although different approaches have been used to evaluate ecosystem services' supply and demand levels, there is little discussion on approaches to match supply and demand. Many indicators have been used to reveal green space inequity and to determine the inequity level, either by combining a Lorenz curve with a Gini coefficient to describe the mismatch of supply and demand, or by proposing new concepts to measure the inequity level [23, 24]. 
Table 1. The four kinds of ecosystem services according to The Millennium Ecosystem Assessment.

\begin{tabular}{|c|c|c|}
\hline Types & Explanations & Examples \\
\hline Provisioning services & Products obtained from ecosystems & Food; Fresh water; Biochemicals \\
\hline Regulating services & Benefits obtained from regulation of ecosystem processes & $\begin{array}{l}\text { Climate regulation; Water regulation; } \\
\text { Water purification }\end{array}$ \\
\hline Supporting services & $\begin{array}{l}\text { Services necessary for the production of all other ecosystem } \\
\text { services }\end{array}$ & Soil formation; Primary production \\
\hline Cultural services & Nonmaterial benefits obtained from ecosystems & Recreation; Aesthetic; Educational \\
\hline
\end{tabular}

Despite the importance of achieving a supplydemand balance, it is largely unknown whether green spaces are equitably distributed in many cities in China [13]. Many people, even governments, believe that the green space supply-demand mismatch can be effectively solved in new districts by advanced urban planning schemes. However, it is still unknown whether new districts built according to urban planning schemes achieve the goal of matching green space supply and demand. Gaps in theory and practice call for a clear framework to match green space ecosystem services supply and residents' demands, and more empirical studies with fine resolution are needed to support the practical projects.

In this paper, we propose a conceptual framework for green space supply and demand matching that can reveal the mismatched conditions in urban areas and help promote social equity. Jinan Western New District, a typical comprehensive new district whose development has been accelerated by a high-speed railway station, is our case study. There exists the spatial-temporal changes in residents' distribution in urban areas, and more evaluation methods rather than demographic data are needed to represent the city's real demands [10, 25]. Hence, this study combines open data with an urban planning layout to represent the residents' distribution. The study chooses "block" as the basic research unit; it is the smallest area surrounded by urban road [26].

\section{The Supply-Demand Matching Conceptual Framework}

In this study, supply and demand refer to the supply of ecosystem services provided by green spaces and users' demands; each type of supply and demand can be discussed from the aspects of quantity and spatial pattern [27]. Before constructing the matching framework, the characteristics of supply and demand and their spatial matching approaches should be clarified. It is vitally important to discover how the ecosystem services flow from the sources to the residents and how these services are used by the residents.

\section{Green Spaces and Ecosystem Services: Supply Sources and Benefiting Areas}

Green spaces are sources of a variety of ecosystem services. According to the Millennium Ecosystem Assessment (MA) [28], ecosystem services can be divided into four categories: provisioning services, regulating services, supporting services and cultural services (more details and explanations are given in Table 1) [29]. Considering that supporting services underlie other services and that provisioning services are significant in rural areas, in urban contexts, regulating services and cultural services provided by urban green spaces have important value [30, 31].

In addition to focusing on ecosystem service benefits, it is important to know how ecosystem services flow from service production sources (green spaces) to where the benefits are realized. In Fisher's study, a classification was developed to describe the spatial characteristics of ecosystem sources and benefiting areas, including the three categories shown in Table 2 and Fig. 2 [32]. Unlike many provisioning services whose products can be delivered from one place to another artificially, many ecosystem services cannot be moved, i.e., the benefiting areas of these services have a close spatial connection to green spaces. For example, recreation services are in-situ; people make use of them only when they can access them, i.e.,

Table 2. Three kinds of ecosystem service divided by spatial characteristics.

\begin{tabular}{|c|c|c|}
\hline Types & Explanations & Examples \\
\hline In situ services & $\begin{array}{c}\text { Locations that services provided and benefits realized } \\
\text { are the same }\end{array}$ & Soil formation; Recreation; \\
\hline Omni-directional services & $\begin{array}{c}\text { Services provided in one location, and benefits surrounded } \\
\text { the location without directional bias }\end{array}$ & $\begin{array}{c}\text { Carbon sequestration; } \\
\text { Climate regulation }\end{array}$ \\
\hline Directional services & $\begin{array}{c}\text { Where the service provision benefits a specific location due to } \\
\text { the flow direction }\end{array}$ & $\begin{array}{c}\text { Water regulation services provided by } \\
\text { forested slopes }\end{array}$ \\
\hline
\end{tabular}




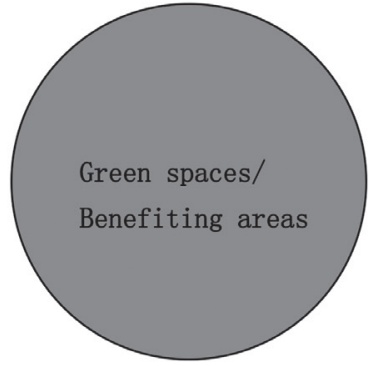

A in-situ services

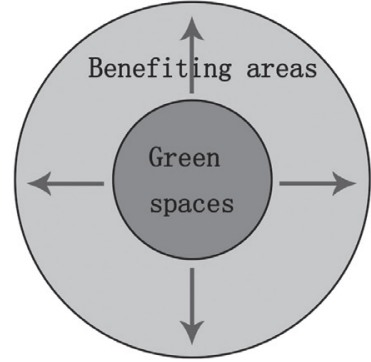

B omni-directional services

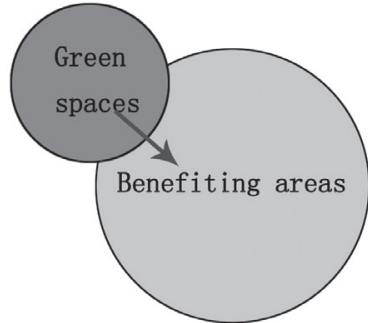

C Directional services

Fig. 2. The spatial patterns of green spaces and benefiting areas.

the benefiting areas of these services are in the green spaces. Many regulating services, however, are omnidirectional services; the benefiting areas are usually bigger than the vegetation areas in green spaces, and their scope varies. As a result, to evaluate the supply scope and quantity, we need to analyze how ecosystem services are delivered from green spaces and the spatial pattern of the benefiting areas.

In this study, the supply-demand matching conceptual framework concentrates on regulating and cultural services, including air purification, temperature regulation, recreation, and education. The spatial distributions of these services are directly related to $t$ heir sources and flows, and are difficult to be transferred artificially. Further understanding of how ecosystem services flow from green spaces to benefitting areas is essential for spatial planning, which might be the most important method for redistributing ecosystem services.

\section{Residents' Location and Traveling Distance: Demand Sources and Demand Flow}

Similar to green spaces and ecosystem services flow, this study considers residents' location as demand sources; residents' travel to ecosystem services benefiting areas can be regarded as demand flow. Different kinds of ecosystem services have different attractions for residents, thus the travel distance that people accept to enjoy different ecosystem services varies. For example, residents are happy to travel a relatively long distance to national parks or heritage sites and may stay overnight in green spaces with ecotourism or heritage protection services but, for daily recreation in public parks, 15 minutes walkable distance from home or office is acceptable [33,34]. This factor is much more related to individual differences than ecosystem conditions [35]. Additionally, ecosystem services, like urban heat island alleviation and air purification, are not attractive enough to drive residents to travel there, so the benefiting areas need to be consistent with residents' distribution. Therefore, identifying users' location and the acceptable traveling distance to a certain kind of ecosystem service are essential factors in mapping their demand degree and area.

\section{Steps of Supply-Demand Spatial Matching}

The conceptual framework for green space supply and demand matching comprises four steps as shown in Fig. 3, and is described in the following sub-sections.

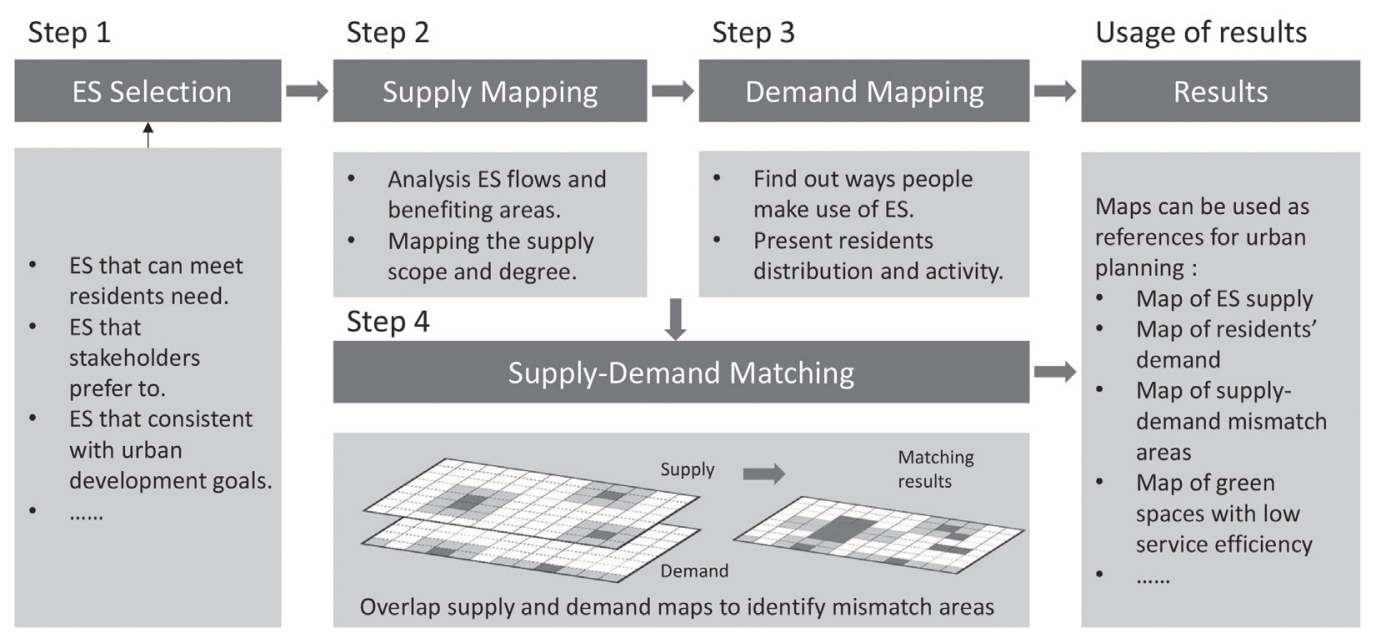

Fig. 3. The conceptual framework for green spaces supply and demand matching. 
The key point is to combine the ecosystem services benefiting areas with residents' travel flow. The first step is to determine which ecosystem services need to be discussed in supply-demand matching, through residents' demands or stakeholders' participation [36]. Different kinds of ecosystem services play different roles in a given city and depend on its environmental and socio-economic characteristics [31, 37]. Then you need to map the provision of ecosystem services, i.e., the benefiting areas of the ecosystem services. In this step, you need to ensure that green spaces and the corresponding ecosystem services are spatially consistent, otherwise the benefiting distance that ecosystem services flow from green spaces need to be studied by field investigation or literature reviews. The third step is to map the area and degree of residents' demands. For this, we need to figure out how the ecosystem services are used by the residents, and whether most residents are willing to take the initiative to enjoy these services. If not, the residents' locations can be regarded as demand areas, otherwise the distance that users are willing to travel needs to be considered. The final step is to match the supply and demand areas spatially. In this, both the supply and demand results need to be standardized and mapped in a unified unit so that results can be compared and matched.

Based on the steps above, this study uses Jinan Western New District as a case study, matching its public parks cultural service supply and the residents' demands. We map the supply and demand with the "block" as the basic unit in order to find the supplydemand mismatch blocks and combine those with field investigation to examine the matching results.

\section{Material and Methods}

\section{Study Areas}

Jinan western new district is in the west of the city, Shandong Province, China. Jinan is located in the northwestern part of Shandong Province (116 $57^{\prime}$ E, $36^{\circ} 40^{\prime} \mathrm{N}$ ), and has a humid continental climate with four well-defined seasons. Being the capital of Shandong Province, Jinan has held sub-provincial administrative status since 1994; it had a population of 6.43 million in 2017. Since 2011, the area of parks in Jinan has continued to grow, but the per capita park area has grown slowly (from $10.9 \mathrm{~m} /$ person in 2011 to $11.79 \mathrm{~m} /$ person in 2017) because of the population expansion.

The study site, Jinan Western New District, is known as the only growth pole in western Jinan. It covers a total area of $450 \mathrm{~km}^{2}$ (Fig. 4). It has been built since 2003 and consists of 7 sub-districts defined by administrative divisions and the conceptual planning scheme. In 2008, the construction of the Jinan Western Railway Station on the Beijing-Shanghai high-speed railway made the Jinan Western Railway Station area the core growth pole of the district. Unlike many other new districts in China, there are still old towns and rural areas in Jinan Western New District. In this paper, old towns refers to towns that were built before the research area was delimited. These towns originally developed from villages, counties or communes since the 1950s and have been urbanized since the 1980s. The newly built areas were planned and built after the Jinan Western New District had been delimited. It should

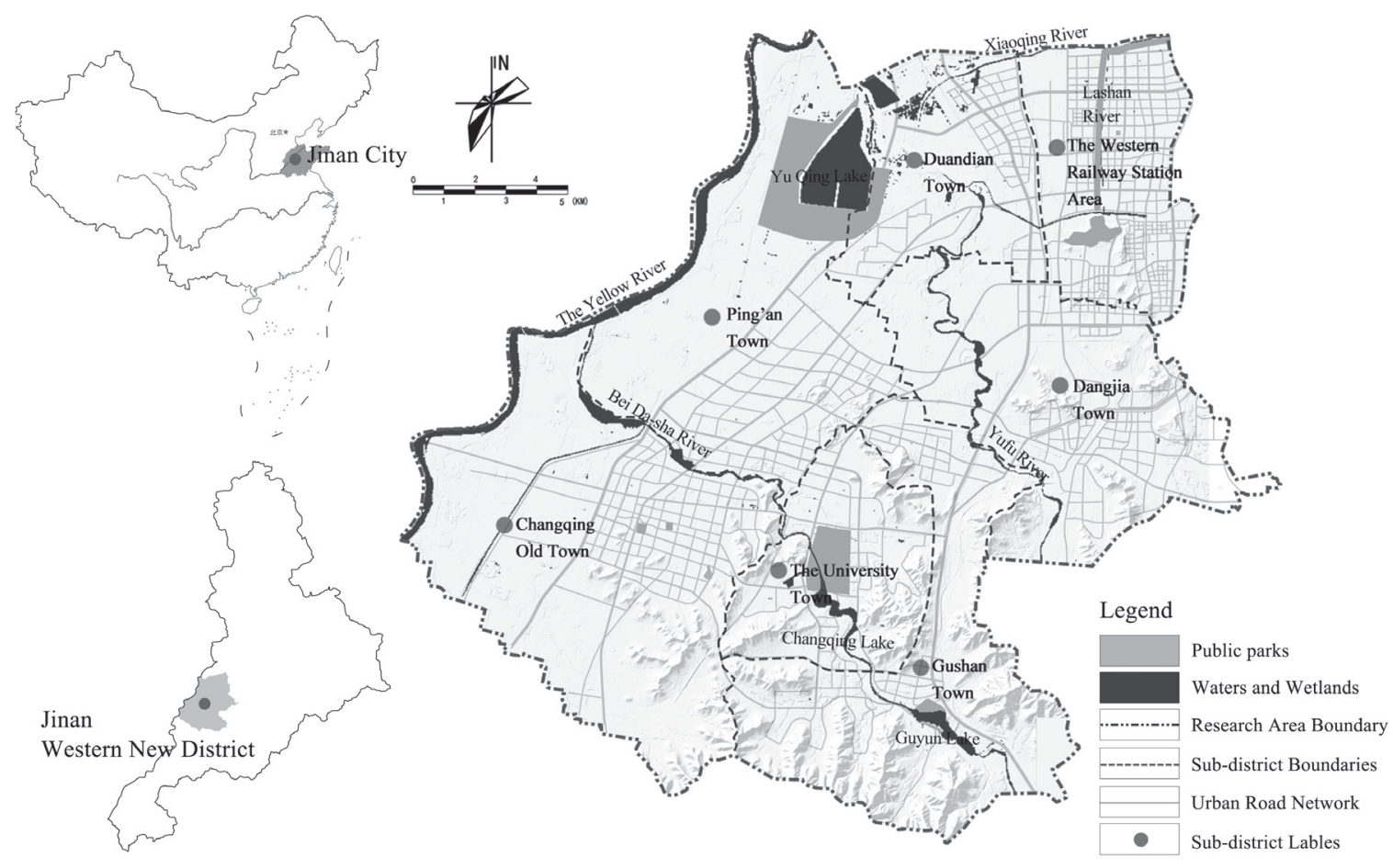

Fig. 4. The location of Jinan western new district and the public parks distribution. 
be noticed that the construction of new towns in Jinan Western New District were based on an advanced urban planning scheme and have undertaken specific urban functions, such as education, business and finance.

Of all the 7 sub-districts, Jinan Western Railway Station area and the university town are newly built areas in 2003 and 2008, respectively, with the aim of stimulating economic growth of the surrounding areas. Changqing old town and Dangjia town are old towns with dense populations, but are not the core of the development. Duandian, Ping'an and Gushan are old towns distributed in the peri-urban area, with a low density of buildings and population. So far, with the construction of two newly built areas completed, a shortage of public parks exists.

Approximately $41.36 \%$ of Jinan Western New District is covered by vegetation, mainly farmland and lowland hills. There are only nine public parks (including one green corridor along the river and one county park) to provide cultural services for residents in the built-up area $\left(108.72 \mathrm{~km}^{2}\right)$. To maintain sustainable development and promote living environment quality, the government is placing great emphasis on the optimization of public park quantity and service efficiency. However, with the rapid expansion of construction land, there is less room for new parks. To make good use of the limited land and improve public park service efficiency, it is essential to identify blocks with a high demand for parks, as a basis to optimize the green spaces system.

\section{Data Sources}

The data for this paper come from several sources. The basic information and land-use of Jinan Western New District are from the Jinan statistical yearbook (2018) and the Jinan Western New District conceptual plan. The public park locations were identified in remote sensing images with $0.5 \mathrm{~m}$ resolution from the National Geography Information Public Service Platform of China (Tiandi Map). The road network of the Jinan Western New District was extracted from the Jinan City road network, which was downloaded in GIS format from Open Street Map in April 2018. In addition, this study has used point of interest (POI) data, one of the most commonly used open data sources in urban research in China. POI is a basic unit of information with specific point coordinates in online map and social networks, with a considerable group of people finding it useful or interesting [38]. Each POI has a corresponding geographic entity in an online map, be it a school, a park, bus stop, or residential district, and the distribution of POI data are considered to have a close relationship with population density in many studies [39]. POI data can also be classified, displayed, and calculated with the support of the GIS platform [40]. In this paper, POI data were obtained from Baidu Map - the largest online map in China; the four vertices' projection coordinates of the rectangle acquisition range are $116.64 \mathrm{E}, 36.69$ $\mathrm{N} ; 116.96$ E, $36.69 \mathrm{~N} ; 116.64 \mathrm{E}, 36.46 \mathrm{~N} ; 116.96 \mathrm{E}$, 36.46 N. The collection date was December 11, 2017, and the total number of POIs is 20,870. POI data have been divided into 17 classes according to their attributes in the Baidu Map, as shown in Table 3.

Multiple steps were undertaken to pre-process the data. First, we digitized all data in the geographic information system (GIS) platform, projecting them under the same coordinate system. Then, Jinan Western New District was divided into 792 blocks according to the road network. The basic study unit is the block, the smallest area surrounded by an urban road, corresponding to the concept of "dikuai" in China, which is often used in urban studies, because it is convenient to link the research results to urban planning. Finally, taking the blocks as the calculation unit, the min-max method was applied for normalizing the evaluated results; each value was assigned to its corresponding block.

\section{Data Analysis}

\section{Ecosystem Services Selection}

In Jinan Western New District, green spaces are mainly distributed in the periphery of built-up areas, and include farmland, forest, and wetland. They can provide a variety of ecosystem services for residents, such as clean water and food, purify air, and places for recreation. In built-up regions, public parks are the most important green spaces in which residents can enjoy a variety of cultural services, including sport, socializing and nature experiences, which can improve

Table 3. The details of the POI data in Jinan western new district.

\begin{tabular}{|c|c|c|c|c|c|}
\hline Class name & Amount & Class name & Number & Class name & Number \\
\hline Government agencies & 1043 & Educational institutions & 205 & Vehicle maintenance shops & 1205 \\
\hline Residential quarters & 1035 & Financial institutions & 534 & Media institutions & 138 \\
\hline Companies and enterprises & 2827 & Restaurants & 3403 & Beauty salons & 394 \\
\hline Shops & 3828 & Hotels & 893 & Entertainment venues & 925 \\
\hline Hospitals and pharmacies & 811 & Life services & 2035 & Sports facilities & 31 \\
\hline Traffic facilities & 1389 & Scenic spots & 174 & Total & 20870 \\
\hline
\end{tabular}


their physical and mental health [41]. In this study, one of the most important cultural services, recreation, was selected as an indicator to reveal the supply-demand mismatch of cultural services provided by public parks, because it is closely related to residents' daily needs and can meet the government's goal of building a livable city.

\section{Cultural Service Supply Evaluation and Mapping}

Most cultural services are in-situ services like recreation, and the traveling distance of users needs to be considered. To simplify the evaluation, we took each park's service scope as the benefiting area; people located within the scope can use the recreation service conveniently. The closer people are to public parks, the time and distance cost to access the park is lower and people can enjoy a higher level of recreation services. Network analysis in ArcGIS was used to draw each park's service scope. We located each park entrance on the road network and set a walking speed to simulate the possible scope that residents can reach by walking 10,15 , and 30 minutes from the park entrances. Each scope can be considered a service benefiting area. To determine the supply level, the ratio of 10-, 15- and 30 -minute walking benefiting areas to block area were calculated. Additionally, a weighted stacking method was used to overlay 10,15 , and 30 minutes walking scope; the weight was decided by urban residents' and experts' judgements.

\section{Urban Residents Demand Evaluation and Mapping}

As resident flow has already been considered when estimating public parks' service scopes, the next step is to identify the demand sources (users' distribution). Blocks with a dense population and a high vitality always have a higher demand for public parks. We chose the POI density and planned land-use layout diversity to represent population density and urban vitality, respectively. The POI density was calculated to determine the degree of population aggregation. First, certain classes highly related to population density were selected. According to Chun's study, some classes of POI have a higher correlation with population density, e.g., beauty salons, hospitals and pharmacies, entertainment venues, residential quarters, restaurants, shops, and educational institutions [42].These classes of POI were distributed in the GIS platform based on their coordinates and joined to the nearest blocks. Finally, we counted the number of POIs in each block and calculated the density by dividing by the block area.

Some areas in Jinan Western New District are now under construction. Although these areas have few residents now, they may be the future core of the region. Considering long-term development, we use the Shannon diversity index (SHDI) to calculate the land-use diversity to express the demand, calculated as follows:

$$
\mathrm{SHDI}_{\mathrm{i}}=-\sum_{\mathrm{k}=1}^{\mathrm{n}}\left[\mathrm{P}_{\mathrm{ik}} \times \ln \left(\mathrm{P}_{\mathrm{ik}}\right)\right]
$$

Each block was numbered and assumed as ' $\mathrm{i}$ ' (i values range from 1 to 792 , the total number of blocks). Similarly, we numbered the land-use type and labelled it ' $k$ '. SHDI ${ }_{i}$ is the Shannon diversity index of the $\mathrm{i}$-th block, and $\mathrm{P}_{\mathrm{ik}}$ is the ratio of the k-type patch area in the i-th block to the block area. The land-use layout of the Jinan Western New District conceptual plan was converted to raster data and segmented into 792 parts according to the blocks. Fragstats 4.1 was used to calculate each block's SHDI. After these steps, the POI density and Shannon diversity index of all blocks were normalized separately and overlaid in equal weight to achieve the final results.

\section{Culture Services Supply-Demand Matching}

The final step is to match the supply and demand evaluations. All data were normalized and divided into five degrees by the method of natural breaks (Jenks). To correspond the supply and demand levels (e.g., to ensure a high-level supply satisfies a highlevel demand), several blocks were sampled for field investigation and residents were interviewed to adjust each level's threshold. The supply and demand maps were spatially associated to identify supply surplus blocks, supply deficit blocks and supply-demand balanced blocks. We thus revealed the mismatches between supply and demand from the aspect of quantity and spatial distribution and tabulated the supply and demand amount of the 7 sub-districts and summarized the distribution characteristics of mismatched blocks.

\section{Results}

\section{Characteristics of Culture Service Supply in Jinan Western New District}

Table 4 shows the maximum, minimum and mean values of recreation services supply in each sub-district. Obviously, the supply levels in newly-built areas are much higher than those in old towns and the peri-urban areas. The maximum values in the western railway station and the university town areas were 12.99 and 9.15 , respectively, which means that in these two subdistricts, park entrances are densely distributed in some blocks and the 10 minute walking scope of each entrance overlapped in these blocks. Conversely, the minimum value for seven sub-districts is 0 , i.e., there are blocks in every sub-district with no access to cultural services; residents living there cannot reach parks in a 30-minute walk. The distribution of public parks might be excessively concentrated in Jinan 
Table 4. The cultural service supply values in the seven sub-districts of Jinan.

\begin{tabular}{|c|c|c|c|c|}
\hline \multirow{2}{*}{\multicolumn{2}{|c|}{ Sub-districts }} & \multicolumn{3}{c|}{ Value of culture service supply } \\
\cline { 2 - 5 } & Mean value & Maximum value & Minimum value \\
\hline \multirow{3}{*}{ Newly-built areas } & The western railway station area & 3.12 & 12.99 & 0 \\
\cline { 2 - 5 } & The university town & 2.83 & 9.15 & 0 \\
\hline \multirow{2}{*}{ Old towns } & Changqing old town & 0.95 & 5.06 & 0 \\
\cline { 2 - 5 } & Dangjia town & 0.22 & 2.19 & 0 \\
\hline \multirow{3}{*}{ Peri-urban areas } & Gushan town & 0.12 & 1.29 & 0 \\
\cline { 2 - 5 } & Ping'an town & 0.29 & 2.74 & 0 \\
\cline { 2 - 5 } & Duandian town & 0.08 & 0.91 & 0 \\
\hline
\end{tabular}

Western New District - especially in newly built areas.

The supply evaluation values were divided into five levels and mapped; the proportions of each level and the maps are shown in Fig. 5. Residents living in deep red blocks have greater opportunity to access public parks. Most blocks in Jinan western new district have a low level of cultural service supply; there are seven cores located in the center of seven sub-districts with a higher supply level than other blocks. Blocks with a high supply level are concentrated in Jinan Western Railway Station area and the university town; there are no blocks with a high supply level in the old towns and peri-urban areas. Although Jinan Western New District has been designated as a new developing core and has been under construction for 15 years, almost no parks are available for residents in peri-urban residential areas.

\section{Characteristics of Resident Demand in Jinan Western New District}

Tables 5 and 6 show the evaluation results of resident demand from POI density and land-use diversity. The POI density reflects current demand for public parks.
The mean value of POI density in the old towns is nearly six times that of the new towns; there is no doubt that the old towns have a higher vitality and greater demand for public parks. The new towns, however, lack population and vitality. Of all the sub-districts, two located in peripheral urban areas have the lowest POI density; the demand for public parks here is lower than in city central areas.

The land-use diversity index indicates the demand for cultural services in future developments and the evaluation results are quite different from POI density. There is no obvious difference between new and old areas in the average value of the land-use diversity index, though the minimum values in the newly built areas are much higher than those of the old towns. The land-use diversity index varies greatly in the old towns, but in the new areas is more balanced (the standard deviations of the land-use diversity index in the two newly built areas are 0.16 and 0.19 , whereas in the two old towns they are 0.48 and 0.61 ). Because of the planning first development mode, the spatial differences of demand level in western railway station and university town areas are relatively small for the future. There is little difference in land-use diversity

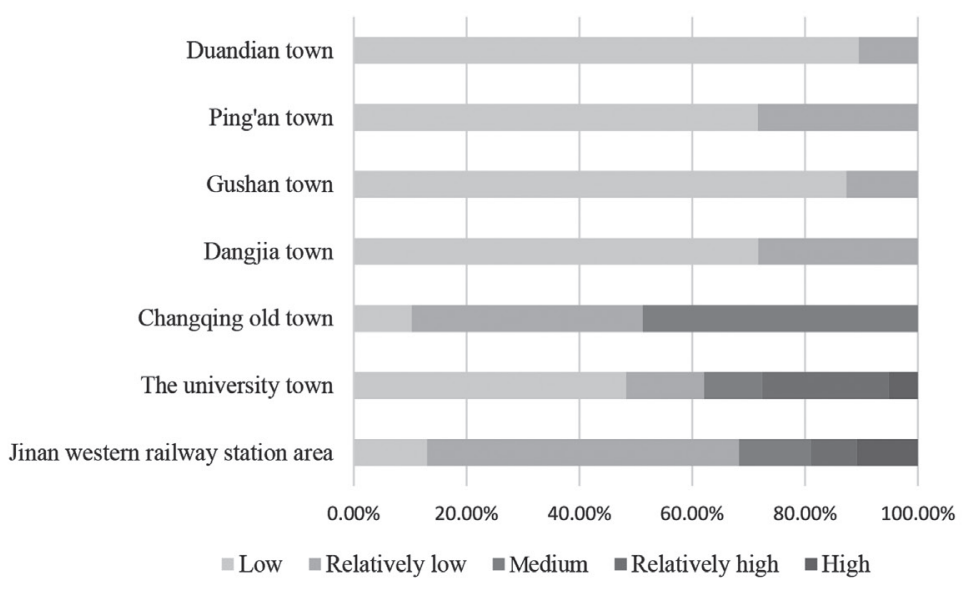

The proportion of 5 levels in each sub-district

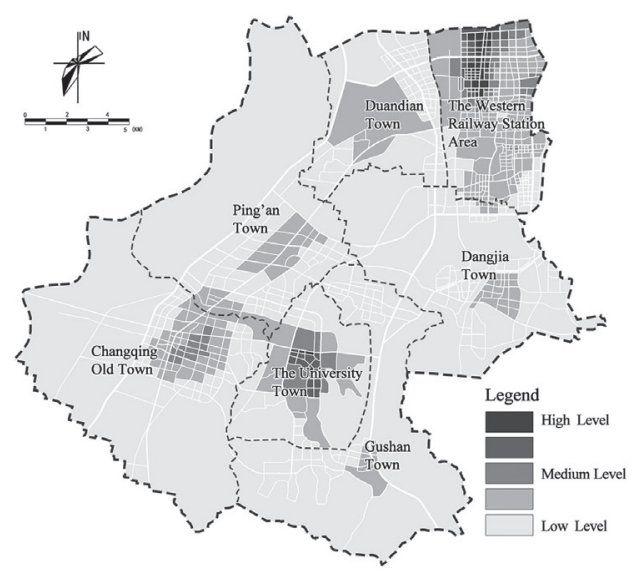

Map of culture service supply

Fig. 5. Cultural service supply level proportion by district. 
Table 5. The POI density values for the seven sub-districts of Jinan.

\begin{tabular}{|c|c|c|c|c|}
\hline \multirow{2}{*}{\multicolumn{2}{|c|}{ Sub-districts }} & \multicolumn{3}{c|}{ Value of residents demand-POI density } \\
\cline { 2 - 5 } & Mean value & Maximum value & Minimum value \\
\hline \multirow{3}{*}{ Newly-built areas } & The western railway station area & 2.25 & 66.33 & 0 \\
\cline { 2 - 5 } & The university town & 1.90 & 37.12 & 0 \\
\hline \multirow{3}{*}{ Old towns } & Changqing old town & 13.92 & 108.86 & 0 \\
\cline { 2 - 5 } & Dangjia town & 12.11 & 307.08 & 0 \\
\hline \multirow{3}{*}{ Peri-urban areas } & Gushan town & 1.72 & 19.32 & 0 \\
\cline { 2 - 5 } & Ping'an town & 0.98 & 6.91 & 0 \\
\cline { 2 - 5 } & Duandian town & 2.70 & 30.21 & 0 \\
\hline
\end{tabular}

Table 6. Land-use diversity values of the seven sub-districts of Jinan.

\begin{tabular}{|c|c|c|c|c|}
\hline \multirow{2}{*}{\multicolumn{2}{|c|}{ Sub-districts }} & \multicolumn{2}{c|}{ Value of residents demand-land-use diversity } \\
\cline { 2 - 5 } & Mean value & Maximum value & Minimum value \\
\hline \multirow{3}{*}{ Newly-built areas } & The western railway station area & 2.00 & 2.35 & 1.55 \\
\cline { 2 - 5 } & The university town & 1.86 & 2.43 & 1.46 \\
\hline \multirow{2}{*}{ Old towns } & Changqing old town & 2.02 & 2.63 & 0.44 \\
\cline { 2 - 5 } & Dangjia town & 1.71 & 2.50 & 0.17 \\
\hline \multirow{3}{*}{ Peri-urban areas } & Gushan town & 1.65 & 2.26 & 0.15 \\
\cline { 2 - 5 } & Ping'an town & 1.70 & 2.44 & 0.45 \\
\cline { 2 - 5 } & Duandian town & 1.90 & 2.45 & 0.45 \\
\hline
\end{tabular}

index between the urban and peri-urban areas; their future demand for public parks is equivalent.

The proportions of each demand level are summarized, mapped, and shown in Fig. 6. Blocks colored deep red have a higher demand for urban parks, and their distribution is consistent with construction land. Compared with the newly built-up areas, the old towns have a higher demand level; $25.98 \%$ and
9.45\% blocks of Changqing and Dangjia old towns, respectively, have a high demand level, whereas the western railway station and the university town areas are $2.72 \%$ and $3.45 \%$, respectively. Peri-urban areas have a lower demand level for recreation services than central areas, which is manifested in the absence of high demand blocks, and the proportion of low demand blocks is higher than central urban areas.

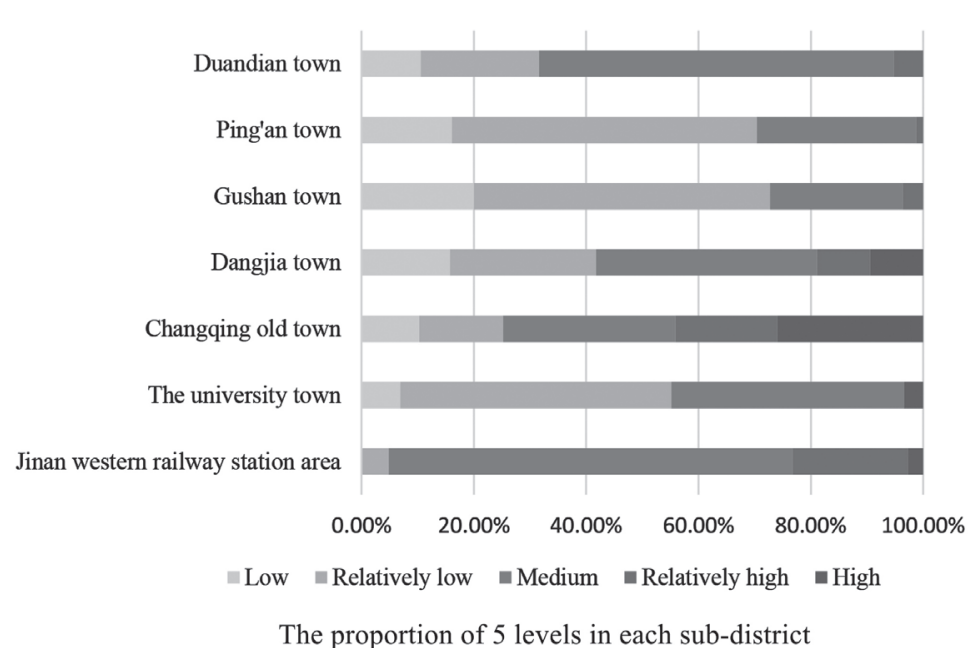

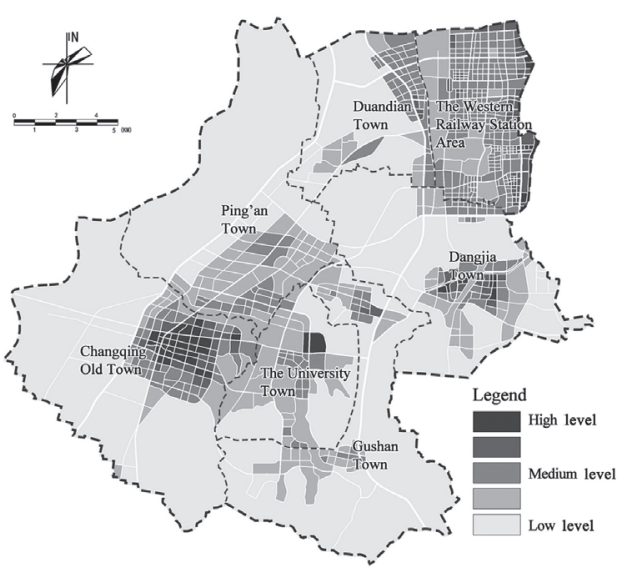

Map of culture service demand

Fig. 6. Cultural service demand levels by district. 


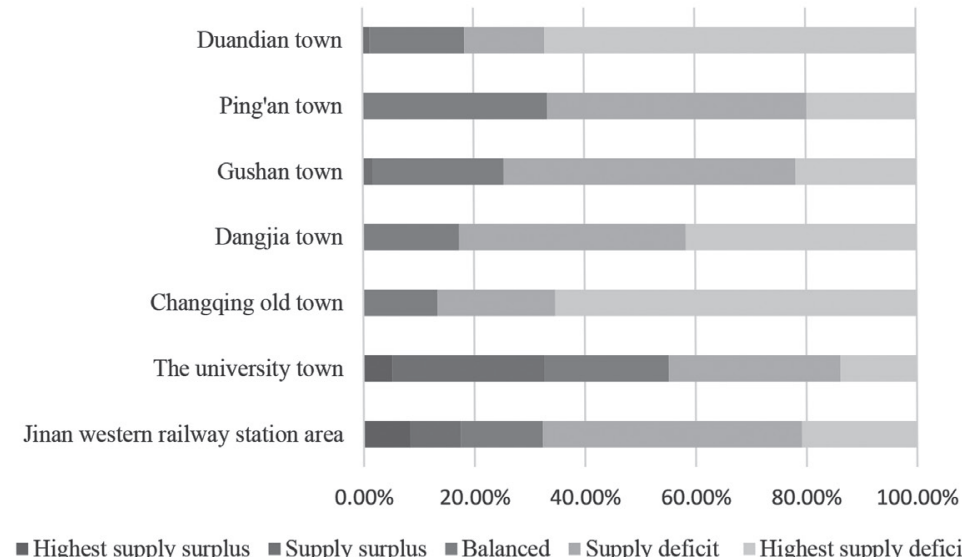

The proportion of 5 levels in each sub-district

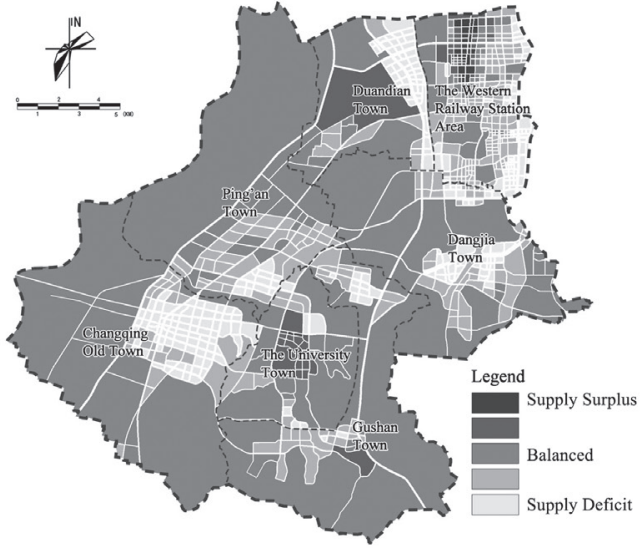

Map of supply-demand matching

Fig. 7. Cultural service supply-demand mismatch level by district.

\section{Supply-Demand Mismatch in Jinan Western New District}

The cultural services supply and demand of each sub-district were normalized and matched as shown in Fig. 7. There is an obvious mismatch between supply and demand in Jinan western new district. All subdistricts - no matter if they are new areas, old towns and peri-urban areas - have blocks with an acute shortage of public parks; old towns are more serious than the newly built and peri-urban areas. For example, $65.35 \%$ of the blocks in Changqing old town and $41.73 \%$ of them in Dangjia town have the highest supply deficit compared with Jinan Western Railway Station and university town areas that have $20.85 \%$ and $13.79 \%$, respectively. Blocks with the highest supply surplus exist only in Jinan Western Railway Station and the university town areas, near a big exhibition park and along the Lashan River. Many blocks in new areas have a balance between supply and demand, but there are still deficit blocks, mainly in fringe areas. Compared with central urban areas, both supply and demand levels in peri-urban areas are lower; the blocks with a supplydemand balance are mainly distributed in non-urban construction regions, with almost no public parks or residents.

In general, old towns located in urban centers have the most urgent need to increase public parks and optimize urban green space systems, followed by old towns in peri-urban areas. In newly built areas, the existing public parks can meet the needs of most people, but more parks are needed in fringe areas.

\section{Discussion}

This study proposes a conceptual framework to match the supply and demand of urban green spaces using Jinan Western New District as the case study and matching its cultural services supply and resident demands. The results indicate that there is a significant mismatch between supply and demand in Jinan Western New District, old towns and peri-urban areas that need more parks. Newly built areas have a better supply of recreation services.

\section{Ecosystem Services Supply and Demand Matching Framework}

Green space efficiency and equity are two aspects that residents and policymakers are concerned about in the context of urban expansion in China [43]. As green space resources are limited, efficiency means obtaining the biggest benefits from limited green spaces, and equity refers to how the benefits are distributed among society [44]. To promote efficiency and equity, the critical issue is matching ecosystem services supply and residents' demands. However, most studies simply regard green spaces as the supply side and they lack consideration of ecosystem services. There are spatial connections and differences between green spaces and the ecosystem services provided by green spaces; ecosystem services can be available on the local and global scale and many services can be artificially transferred from their sources to places where people live [30]. The spatial characteristics in generation, transmission, and consumption vary among ecosystem services and need to be considered when evaluating and mapping. In many supply-demand matching studies, service type is not clearly defined. The type of ecosystem service can be determined either based on residents' and governments' requirements and regional development goals, or through analyzing ecosystem service bundles to identify the leading ecosystem service at the study site [45].

In urban construction areas, studies have mainly concentrated on cultural and regulating services; these in-situ services are location-sensitive and can be distributed through spatial planning. Although many studies have not exactly raised the issue of supply 
and demand, their research methods and objectives are closely related to supply-demand matching, either choosing green space accessibility as an indicator to present supply-demand inequity, or matching certain kinds of ecosystem services provided by green spaces with social groups or stakeholder preferences [46, 47]. Despite the abundance of research about green space supply-demand matching, a systematic framework to match supply and demand has not been established. It is of theoretical and practical significance to propose a conceptual framework of green space supply and demand matching.

In the supply-demand matching framework we propose, benefiting areas of selected ecosystem services need to be mapped and the spatial distribution of users has to be identified. Only when the benefiting areas overlap demand areas can the supply be used effectively and resident demands satisfied. This view is widely accepted and embodied in many studies, especially in park accessibility evaluation research and studies to match green spaces service scope and resident distribution [17, 48]. Because of the uncertain spatial pattern and the corresponding consumption ways, we did not classify and summarize ways to evaluate and map each kind of ecosystem service in this paper. This provides potential future research opportunities to improve the framework. More literature reviews of ecosystem services and users' flows are needed. The detailed framework can act as a guideline for supplydemand matching of the different kinds of ecosystem service. Practical projects are essential for examining its utility.

\section{The Rationality of Indicators Selected in the Case Study}

In this case study, we match the supply of and demand for public parks recreation services. The service scope of public parks is regarded as ecosystem services benefiting areas; the people located in these areas can enjoy recreation services by a short walk. Network analysis based on ArcGIS was used to evaluate the service scope that has been used in many studies [17, 49]. Because residents' flow has been considered when measuring public park supply, we only need to consider residents' distribution when measuring demand areas and degree.

POI density and land-use diversity were selected as indicators to represent residents' distribution. As a spatial carrier of geographic entities in a city, the distribution of POIs has a high correlation with demographics $\left(\mathrm{R}^{2}>0.8\right)$; of all the categories, beauty salons, medical treatment, and recreation, have high correlations with population density $\left(\mathrm{R}^{2}>0.89\right)$, whereas tourist attractions, hotels, and government agencies have a low correlation $\left(\mathrm{R}^{2}<0.5\right)[42,50]$. Compared with statistics from governments, open data like POI are easier to obtain and can be analyzed with fine resolution, which filled the gap between fast-growing cities and slowly renewing traditional data $[26,51]$. In many studies, the satisfying results achieved via POI density and diversity to represent population density and urban vitality can act as proof of its utility $[52,53]$.

Land-use diversity is a suitable indicator to represent urban vitality. Many studies show that areas with mixed land-use always have mixed functions, high dynamics, and high population density [54]. As a result, urban planning layout with high land-use diversity is more likely to form high population density areas and need more public parks. The Shannon diversity index (SHDI) is an indicator widely used in land-use diversity measurement along with POI density to evaluate urban vitality $[52,55]$.

The Shortage and Unbalanced Distribution of Green Spaces in Jinan Western New District

The supply-demand mismatch of cultural services provided by public parks exists in every sub-district in Jinan Western New District, especially in the old towns. In the conceptual planning scheme, the newly built areas act as growth poles taking on the role to stimulate other areas' development and improve the living environment of the whole region. However, after more than 15 years of construction, the results show that public park distribution does not meet the government's and residents' expectations. The conceptual planning scheme proposed building a low-carbon, livable residential environment; until now, this goal has not been achieved in the newly built areas, much less in the old towns and peri-urban areas. The spatial planning proposed before the new town construction improved the green space shortage and unevenness, but the distribution of parks in the new areas is too aggregated; people living in margin blocks have to travel long distances to the nearest park.

The findings can play an important role in green space system optimization in Jinan Western New District. For example, to achieve green space equity and improve service efficiency, new parks are supposed to be located in blocks with crowded people and few cultural services, such as the central area of old towns and peripheral parts of newly built areas. To meet the needs of future development, more public parks are needed in urban renewal in peri-urban areas.

\section{Conclusions}

This paper proposes a framework for matching ecosystem services supply and resident demands and clarify the steps to identify supply-demand mismatch within urban areas. We consider that understanding the generation, transmission and consumption of different ecosystem services is the key to matching supply and demand. The framework can be used to reveal green inequity and identify low-efficiency green spaces and can help optimize human well-being with nature in 
urban areas. To practice the framework, we take Jinan Western New District as an example and match public park supply and resident demands for cultural services. We evaluated and mapped the mismatch, which is summarized as follows: 1) Although Jinan western new district has been designated and has been under construction for 15 years, a supply-demand mismatch commonly exists in urban proper and peri-urban areas; 2) public parks are concentrated in newly built areas; the supply-demand mismatch is less than that in old towns and peri-urban areas; 3) more public parks are needed in Jinan Western New District - especially in the old towns.

In future studies, we plan to improve the framework by detailed supply and demand evaluation as well as exploring more ways to match different kinds of ecosystem services. Additionally, more practical projects are needed to test the detailed framework, and more field investigations are essential for examining the matching results.

\section{Acknowledgements}

The research and writing activities pertaining to this article were supported by the China National R \& D Program "building strong ecological security patterns through elevating green infrastructure levels of ecosystem services" (No. 2017YFC0505705), and Program of Shandong Provincial Natural Science Foundation, China "Research on the response mechanism and planning technology logic of urban green infrastructure based on multi-source data fusion" (No. ZR2019MEE048).

\section{Conflict of Interest}

The authors declare no conflict of interest.

\section{References}

1. ZHU M., ZHOU C. Progress of domestic and foreign new urban district development theories. Tropical Geography, 33 (03), 363, 2013 [In Chinese].

2. ZHU M., ZHOU C. The evolutional course, character, and mechanism of Chinese new urban district since 1978. Modern Urban Research, 27 (09), 80, 2012 [In Chinese].

3. QIU Y. Thinking about the out-of-control city scale: when to stop "unorderly spreading" in urban planning. Chinese Social Science Net. Retrieved from http://www.cssn.cn/ dybg/gqdy_sh/201510/t20151008_2485434.shtml, 2015 [In Chinese].

4. RIGOLON A., BROWNING M., JENNINGS V. Inequities in the quality of urban park systems: an environmental justice investigation of cities in the United States. Landscape and Urban Planning, 178 (11), 156, 2018.

5. GALAGODA R.U., JAYASINGHE G.Y., HALWATURA R.U., RUPASINGHE H.T. The impact of urban green infrastructure as a sustainable approach towards tropical micro-climatic changes and human thermal comfort. Urban Forestry and Urban Greening, 34 (3), 1, 2018.

6. KACZYNSKI A.T., POTWARKA L.R., SAELENS P.B.E Association of park size, distance, and features with physical activity in neighborhood parks. American Journal of Public Health, 98 (8), 1451, 2008.

7. LOPERFIDO J.V., NOE G.B., JARNAGIN S.T., HOGAN D.M. Effects of distributed and centralized stormwater best management practices and land cover on urban stream hydrology at the catchment scale. Journal of Hydrology, 519 (PC), 2584, 2014.

8. MORIMOTO Y. Biodiversity and ecosystem services in urban areas for smart adaptation to climate change: "Do you Kyoto"? Landscape and Ecological Engineering, 7 (1), 9, 2011.

9. ZHANG S., ZHOU W. Recreational visits to urban parks and factors affecting park visits: Evidence from geotagged social media data. Landscape and Urban Planning, 180 (12), 27, 2018.

10. WANG Y.C., SHEN J.K., XIANG W.N. Ecosystem service of green infrastructure for adaptation to urban growth: function and configuration. Ecosystem Health and Sustainability, 4 (5), 132, 2018.

11. ALMOHAMAD H., KNAACK A.L., HABIB B.M. Assessing spatial equity and accessibility of public green spaces in Aleppo City, Syria. Forests, 9 (11), 2018.

12. NESBITT L., MEITNER M.J., GIRLING C., SHEPPARD S.R.J., LU Y. Who has access to urban vegetation? A spatial analysis of distributional green equity in $10 \mathrm{US}$ cities. Landscape and Urban Planning, 181 (1), 51, 2019.

13. XIAO Y., WANG Z., LI Z., TANG Z. An assessment of urban park access in Shanghai - Implications for the social equity in urban China. Landscape and Urban Planning, 157 (1), 383, 2017.

14. YAHDJIAN L., SALA O.E., HAVSTAD K.M. Rangeland ecosystem services: Shifting focus from supply to reconciling supply and demand. Frontiers in Ecology and the Environment, 13 (1), 44, 2015.

15. PENG J., XIE P., LIU Y., YANG Y. Zoning for the construction of green space ecological networks in Guangdong province based on the supply and demand of ecosystem services. Acta Ecologica Sinica, 37 (13), 4562, 2017 [In Chinese].

16. CETIN M. Using GIS analysis to assess urban green space in terms of accessibility: Case study in Kutahya. International Journal of Sustainable Development and World Ecology, 22 (5), 420, 2015.

17. WRIGHT WENDEL H.E., ZARGER R.K., MIHELCIC J.R. Accessibility and usability: Green space preferences, perceptions, and barriers in a rapidly urbanizing city in Latin America. Landscape and Urban Planning, 107 (3), 272, 2012.

18. SCHOLTE S.S.K., VAN TEEFFELEN A.J.A., VERBURG P.H. Integrating socio-cultural perspectives into ecosystem service valuation: A review of concepts and methods. Ecological Economics, 114 (6), 67, 2015.

19. CHEN Z., LIU S. Real-time environmental affective experience assessment via wearable sensors. Chinese Landscape Architecture, 34 (03), 12, 2018 [In Chinese].

20. RAHNEMA S., SEDAGHATHOOR S., ALLAHYARI M.S., DAMALAS C.A., BILALI H.EL. Preferences and emotion perceptions of ornamental plant species for green space designing among urban park users in Iran. Urban Forestry and Urban Greening, 39 (8), 98, 2019.

21. RAHMAN K.M.A., ZHANG D. Analyzing the level of accessibility of public urban green spaces to different 
socially vulnerable groups of people. Sustainability (Switzerland), 10 (11), 2018.

22. FANG J., LIU S., WANG D., ZHANG Y. Supply-demand service analysis of park in shanghai by mobile phone signaling data. Landscape Architecture, 1530 (11), 35, 2017 [In Chinese].

23. HECKERT M., ROSAN C.D. Developing a green infrastructure equity index to promote equity planning. Urban Forestry and Urban Greening, 19 (9), 263, 2016.

24. TANG Z., GU S. An evaluation of social performance in the distribution of urban parks in the central city of Shanghai-From Spatial Equity to Social Equity. Urban Planning Forum, 2 (02), 48, 2015 [In Chinese].

25. ZHONG W., WANG D., XIE D., YAN L. Dynamic characteristics of Shanghai's population distribution using cell phone signaling data. Geographical Research, 36 (05), 972, 2017 [In Chinese].

26. LONG Y., WU K., WANG J., LIU X. Big Models: A novel paradigm for urban and regional studies. Urban Planning Forum, 6 (06), 52, 2014 [In Chinese].

27. WANG Y., SHEN J., PENG Z., XIANG W. The optimization of green infrastructure ecosystem services adapted to urban growth. Chinese Landscape Architecture, 34 (10), 45, 2018 [In Chinese].

28. MOONEY H.A., CROPPER A., REID W. The millennium ecosystem assessment: What is it all about? Trends in Ecology and Evolution, 19 (5), 221, 2004.

29. FISHER B., KERRY TURNER R. Ecosystem services: Classification for valuation. Biological Conservation, 141 (5), 1167, 2008.

30. BOLUND P., HUNHAMMAR S. Ecosystem services in urban areas. Ecological Economics, 29 (2), 293, 1999.

31. GÓMEZ-BAGGETHUN E., BARTON D.N. Classifying and valuing ecosystem services for urban planning. Ecological Economics, 86 (2), 235, 2013.

32. FISHER B., TURNER R.K., MORLING P. Defining and classifying ecosystem services for decision making. Ecological Economics, 68 (3), 643, 2009.

33. REINIUS S.W., FREDMAN P. Protected areas as attractions. Annals of Tourism Research, 34 (4), 839, 2007.

34. P., T., J., G., J.D., I. Splashpads, swings, and shade: Parents' preferences for neighbourhood parks. Canadian Journal of Public Health, 98 (3), 198, 2007.

35. NAHUELHUAL L., CARMONA A., LOZADA P., JARAMILLO A., AGUAYO M. Mapping recreation and ecotourism as a cultural ecosystem service: An application at the local level in Southern Chile. Applied Geography, 40 (6), 71, 2013.

36. PAETZOLD A., WARREN P.H., MALTBY L.L. A framework for assessing ecological quality based on ecosystem services. Ecological Complexity, 7 (3), 273, 2010.

37. BURKHARD B., KROLL F., NEDKOV S., MÜLLER F. Mapping ecosystem service supply, demand and budgets. Ecological Indicators, 21 (10), 17, 2012.

38. JIANG S., ALVES A., RODRIGUES F., FERREIRA J., PEREIRA F.C. Mining point-of-interest data from social networks for urban land use classification and disaggregation. Computers, Environment and Urban Systems, 53 (9), 36, 2015.

39. YANG X., YE T., ZHAO N., CHEN Q., YUE W., QI J., JIA P. Population mapping with multisensor remote sensing images and point-of-interest data. Remote Sensing, 11 (5), 2019.
40. XU Z., GAO X. A novel method for identifying the boundary of urban built-up areas with POI data. Acta Geographica Sinica, 71 (6), 928, 2016 [In Chinese].

41. ZHANG H., CHEN B., SUN Z., BAO Z. Landscape perception and recreation needs in urban green space in Fuyang, Hangzhou, China. Urban Forestry and Urban Greening, 12 (1), 44, 2013.

42. CHUN J., ZHANG X., HUANG J., ZHANG P. A gridding method of redistributing population based on POIs. Geography and Geo-Information Science, 34 (04), 83, 2018 [In Chinese].

43. HE J., YI H., LIU J. Urban green space recreational service assessment and management: A conceptual model based on the service generation process. Ecological Economics, 124 (4), 59, 2016.

44. CHEN J., XIAO Y. Evaluating the efficiency and equity of urban green space in global city - A case of Shanghai, China. Urbanism and Architecture, 16 (01), 17, 2019 [In Chinese].

45. AMENT J.M., MOORE C.A., HERBST M., CUMMING G.S. Cultural ecosystem services in protected areas: understanding bundles, trade-offs, and synergies. Conservation Letters, 10 (4), 439, 2017.

46. LA ROSA D., TAKATORI C., SHIMIZU H., PRIVITERA R. A planning framework to evaluate demands and preferences by different social groups for accessibility to urban greenspaces. Sustainable Cities and Society, 36 (1), 346, 2018.

47. MITCHELL R., POPHAM F. Effect of exposure to natural environment on health inequalities: an observational population study. The Lancet, 372 (9650), 1655, 2008.

48. LEE G., HONG I. Measuring spatial accessibility in the context of spatial disparity between demand and supply of urban park service. Landscape and Urban Planning, 119 (11), 85, 2013.

49. COMBER A., BRUNSDON C., GREEN E. Using a GISbased network analysis to determine urban greenspace accessibility for different ethnic and religious groups. Landscape and Urban Planning, 86 (1), 103, 2008.

50. XU L., YAN M. Population simulation study of Nanjing streets from multi-source information and multi-scale perspective. Bulletin of Surveying and Mapping, (02), 71, 2019 [In Chinese].

51. KHARRAZI A., QIN H., ZHANG Y. Urban big data and sustainable development goals: Challenges and opportunities. Sustainability (Switzerland), 8 (12), 2016.

52. YUE Y., ZHUANG Y., YEH A.G.O., XIE J.Y., MA C.L., LI Q.Q. Measurements of POI-based mixed use and their relationships with neighbourhood vibrancy. International Journal of Geographical Information Science, 31 (4), 658, 2017.

53. ZENG C., SONG Y., HE Q., SHEN F. Spatially explicit assessment on urban vitality: Case studies in Chicago and Wuhan. Sustainable Cities and Society, 40 (7), 296, 2018.

54. SHI B., YANG J. Scale, distribution, and pattern of mixed land use in central districts: A case study of Nanjing, China. Habitat International, 46 (4), 166, 2015.

55. MANAUGH K., KREIDER T. What is mixed use? Presenting an interaction method for measuring land use mix. Journal of Transport and Land Use, 6 (1), 63, 2013. 
